\title{
Pro-inflammatory effects of human apatite crystals extracted from patients suffering from calcific tendinopathy
}

Julien Herman ${ }^{1,2}$, Benoit Le Goff ${ }^{1,2}$, Julien De Lima ${ }^{1}$, Régis Brion ${ }^{1,3}$, Catherine Chevalier ${ }^{1}$, Frédéric Blanchard ${ }^{1+}$ and Christelle Darrieutort-Laffite ${ }^{1,2,4^{*}+}$ (D)

\begin{abstract}
Background: Calcific tendonitis of the rotator cuff is due to carbonated apatite deposits in the shoulder tendons. During the evolution of the disease, an acute inflammatory episode may occur leading to the disappearance of the calcification. Although hydroxyapatite crystal-induced inflammation has been previously studied with synthetic crystals, no data are available with calcifications extracted from patients suffering from calcific tendinopathy. The objective of the study was to explore the inflammatory properties of human calcifications and the pathways involved.
\end{abstract}

Methods: Human calcifications and synthetic hydroxyapatite were used in vitro to stimulate human monocytes and macrophages, the human myeloid cell line THP-1, and human tenocytes. The release of IL-1 $\beta$, IL-6, and IL-8 by cells was quantified by ELISA. The gene expression of pro- and anti-inflammatory cytokines was evaluated by quantitative PCR. NF-kB activation and NLRP3 involvement were assessed in THP-1 cells using a NF-kB inhibitor and a caspase-1 inhibitor. The inflammatory properties were then assessed in vivo using a mouse air pouch model.

Results: Human calcifications were able to induce a significant release of IL-1 $\beta$ when incubated with monocytes, macrophages, and THP-1 only if they were first primed with LPS (monocytes and macrophages) or PMA (THP-1). Stimulation of THP-1 by human calcifications led to similar levels of IL-1 $\beta$ when compared to synthetic hydroxyapatite although these levels were significantly inferior in monocytes and macrophages. The patient's crystals enhanced mRNA expression of pro- $/ L-1 \beta$, as well as $I L-18, N F-k B$, and TGF $\beta$ when IL-6 and TNFa expression were not. IL-1 $\beta$ production was reduced by the inhibition of caspase-1 indicating the role of NLRP3 inflammasome. In vivo, injection of human calcifications or synthetic hydroxyapatite in the air pouch led to a significant increase in membrane thickness although significant overexpression of IL-1 $\beta$ was only observed for synthetic hydroxyapatite.

(Continued on next page)

\footnotetext{
* Correspondence: christelle.darrieutort@univ-nantes.fr

${ }^{\dagger}$ Frédéric Blanchard and Christelle Darrieutort-Laffite are co-senior authors.

${ }^{1}$ INSERM UMR1238, Bone Sarcoma and Remodeling of Calcified Tissues,

Faculté de Médecine de Nantes, 1 rue Gaston Veil, 44035 Nantes Cedex 1,

France

${ }^{2}$ Rheumatology Department, Nantes University Hospital, 44093 Nantes,

France

Full list of author information is available at the end of the article
}

(c) The Author(s). 2021 Open Access This article is licensed under a Creative Commons Attribution 4.0 International License, which permits use, sharing, adaptation, distribution and reproduction in any medium or format, as long as you give appropriate credit to the original author(s) and the source, provide a link to the Creative Commons licence, and indicate if changes were made. The images or other third party material in this article are included in the article's Creative Commons licence, unless indicated otherwise in a credit line to the material. If material is not included in the article's Creative Commons licence and your intended use is not permitted by statutory regulation or exceeds the permitted use, you will need to obtain permission directly from the copyright holder. To view a copy of this licence, visit http://creativecommons.org/licenses/by/4.0/ The Creative Commons Public Domain Dedication waiver (http://creativecommons.org/publicdomain/zero/1.0/) applies to the data made available in this article, unless otherwise stated in a credit line to the data. 
(Continued from previous page)

Conclusions: As synthetic hydroxyapatite, human calcifications were able to induce an inflammatory response resulting in the production of $I \mathrm{~L}-1 \beta$ after NF-kB activation and through NLRP3 inflammasome. In some experiments, $\mathrm{IL}-1 \beta$ induction was lower with human calcifications compared to synthetic apatite. Differences in size, shape, and protein content may explain this observation.

Keywords: Apatite, Rotator cuff tendons, Interleukin-1, Inflammasome, Air pouch model

\section{Background}

Calcific tendonitis of the rotator cuff is due to carbonated apatite deposits in the shoulder tendons. It is a frequent cause of shoulder pain as calcific deposits are found in 10 to $42 \%$ of chronic painful shoulders [1]. Pain experienced by patients suffering from calcific tendonitis can affect their work life and daily activities. Calcific deposits appear between the tendon fibers after the formation of a fibrocartilaginous metaplasia containing chondrocyte-like cells [2]. These cells, derived from tenocytes, are able to mineralize the matrix through the action of alkaline phosphatase [3]. During the evolution of the disease, an acute inflammatory episode may occur leading to the disappearance of the calcification. This episode is characterized by the rapid onset of severe pain and restriction of motion of the affected joint. The release of crystals in the subacromial bursa causes an acute bursitis responsible for this acute clinical presentation. Histological studies of calcific tendonitis have shown macrophages and multinucleated cells around brokenup calcium deposits; this would suggest their involvement in the initiation of the resorptive phase $[4,5]$. Indeed, these macrophages contained mineral [5], and the multinucleated giant osteoclast-like cells expressed tartrate-resistant acid phosphatase (TRAP) and cathep$\sin \mathrm{K}$, both involved in bone resorption [6].

Hydroxyapatite crystal-induced inflammation has been previously studied: in vitro and in vivo, synthetic hydroxyapatite was able to induce IL-1 $\beta$ and IL-18 release via the activation of the NOD-like receptor family, pyrin domain containing 3 (NLRP3) inflammasome [7-10] although tumor necrosis factor (TNF) seemed not to be implicated in this inflammatory response. In general, microcrystals like apatite, calcium pyrophosphate dihydrate (CPPD), or monosodium urate (MSU) crystals induce an acute inflammatory reaction mainly orchestrated by IL$1 \beta$. After crystal contact and detection by macrophages, IL-1 $\beta$ production and release occur (1) through nuclear factor-kappa B (NF-kB) activation necessary for pro-IL$1 \beta$ production and (2) through NLRP3 and caspase-1 activation to cleave pro-IL-1 $\beta$ into mature IL- $1 \beta$. It is then released into the extracellular environment through the damaged membranes of dying macrophages [11, 12]. However, in all these data, the authors used synthetic crystals, and there is no data about the proinflammatory effects induced by carbonated apatite crystals extracted from patients suffering from calcific tendinopathy. Yet, human calcifications may differ from synthetic apatite through different particle size, shape, and a rich protein content comprising most notably several proteins implicated in immune regulation, ossification, or inflammation [3,13]. It is not known if these components could influence the inflammatory response induced by crystals. Since calcifications from patients differ from synthetic apatite, the objective of the study was to assess the proinflammatory effects of patients' crystals by studying the synthesis of pro-inflammatory cytokines, in particular IL- $1 \beta$, and the underlying mechanisms, focusing on NF$\kappa \mathrm{B}$ and NLRP3 inflammasome activation.

\section{Methods}

\section{Crystal preparation}

Human crystals from calcific tendonitis were collected from symptomatic patients by ultrasound-guided needle lavage and stored in phosphate-buffered saline (PBS) at $-80^{\circ} \mathrm{C}$ as previously described [3]. All patients enrolled gave their formal consent. Synthetic hydroxyapatite crystals (sHA) (REF-289396, Millipore Sigma, Switzerland) were first crushed using a mortar and pestle to obtain a powder close to the human crystals. Scanning electron microscopy was performed with a TM300 microscope (Hitachi, Japan) for further characterization. Human crystals and synthetic hydroxyapatite were diluted and dispersed by brief sonication in a serum-free medium for in vitro experiments and in PBS for in vivo experiments.

\section{Cells}

Human monocytic leukemia cells (THP-1, American Type Culture Collection, USA) were cultured in RPMI medium (Eurobio, France) with $10 \%$ of fetal bovine serum (FBS, Thermo Scientific, USA) and 1\% penicillin/ streptomycin (Lonza, Suisse). They were primed for $6 \mathrm{~h}$ with phorbol 12-myristate 13-acetate (PMA, $0.5 \mu \mathrm{M}$, Sigma-Aldrich, USA), washed with PBS twice, then plated in 96-well plates at 50,000 cells/well and left overnight in complete media before crystal stimulation as described previously [11].

Peripheral blood CD14+ cells were extracted from healthy donors' samples. Peripheral blood mononuclear 
cells were isolated from the blood samples obtained from the "Etablissement Français du Sang" by centrifugation over Ficoll gradient (Sigma-Aldrich). CD14+ cells were magnetically labeled with CD14 microbeads and positively selected by the MACS technology (Miltenyi Biotec, Germany). CD14+ cells were CD3- by flow cytometry (purity $\geq 95 \%$ ). For the experiments using monocytes, cells were plated (50,000 cells/well, 96-well plates) in $\alpha$ MEM medium (Thermo Fisher) with 10\% FBS and $1 \%$ of penicillin/streptomycin. For macrophages, monocyte cells were incubated in granulocytemacrophage colony-stimulating factor (GM-CSF) (25 $\mathrm{ng} / \mathrm{ml})$ and interferon gamma $(\mathrm{IFN}-\gamma)(50 \mathrm{ng} / \mathrm{ml})$ during 96h or in macrophage colony-stimulating factor (MCSF) $(25 \mathrm{ng} / \mathrm{ml}$ ) during $72 \mathrm{~h}$ (all from R\&D Systems, USA). All cells (monocytes or macrophages) were then washed once with PBS and were stimulated or not with lipopolysaccharide (LPS) (Sigma-Aldrich) at $0.1 \mu \mathrm{M}$ overnight and washed with PBS twice before crystal stimulation [7].

Tenocyte-like cells were extracted from the rotator cuff tendons as previously described [3]. They were plated in RPMI medium with $10 \%$ of FBS (5000 cells/ well, 96-well plate) and primed by LPS at $1 \mu \mathrm{g} / \mathrm{ml}$ overnight then washed with PBS twice before crystal stimulation.

Primed THP-1, monocytes, macrophages, and tenocytes were stimulated at the indicated times with human calcifications or synthetic apatite in an FBS-free medium. For some experiments, THP-1 cells were incubated with an inhibitor of NF-kB (BAY-11-7085, 10 $\mu \mathrm{M}$, SigmaAldrich) or an inhibitor of caspase-1 (Z-YVAD-FMK, 10 $\mu \mathrm{M}$, Sigma-Aldrich) $30 \mathrm{~min}$ before crystal stimulation. After crystal stimulation, supernatants were collected for cytokine quantification, and cells were analyzed for viability assay (WST-1, TaKaRa Bio, France), protein expression, or gene expression.

\section{Air pouch model}

Animal experiments were carried out in accordance with the institutional guidelines and were approved by the French ethical committee CEEA Pays de la Loire and by local veterinary services (Approval number APAF IS\#4969-2016041411376797v3). Seven-week-old female BALB/c mice and C57BL/6 mice (Janvier Labs, France) were used in the experiments. Mice were housed under standards conditions. A subcutaneous air pouch was created by injecting $3 \mathrm{ml}$ (day 0 ) and $2 \mathrm{ml}$ (day 3) of sterile air into the dorsal skin of the mice under isoflurane anesthesia. At day 7, crystals prepared as described above were diluted in $1 \mathrm{ml}$ of sterile PBS and injected in the air pouch of the anesthetized mice. After 6 and 24 h, mice were sacrificed, and the membranes of the air pouch were dissected. For each mouse, part of the membrane was fixed for histology and immunohistochemistry, and the other part was dry frozen in liquid nitrogen for gene expression quantification.

\section{Cytokine quantification}

ELISA kits for IL-1 $\beta$, IL-6, and IL-8 (R\&D Systems) were used for cytokine quantification in supernatants.

\section{Reverse transcription-polymerase chain reaction (RT-PCR)}

THP-1 total RNA was extracted using the NucleoSpin RNA Plus kit (Macherey-Nagel, Germany) while air pouch membrane total RNA was extracted using the NucleoSpin Set for NucleoZOL (Macherey-Nagel) after Turrax crushing.

First-strand cDNA was synthesized from $1 \mu \mathrm{g}$ total RNA using the Maxima $\mathrm{H}$ Minus First Strand cDNA Synthesis Kit (Thermo Scientific). Quantitative PCR was performed using SYBR Select Master Mix (Applied Biosystems, USA) and carried out on a CFX96 Real-Time PCR Detection System (Bio-Rad, USA). Primers used are reported in Supplementary Table 1. Resultant cycle threshold $(\mathrm{Ct})$ values were normalized to the invariant control, hypoxanthine-guanine phosphoribosyl transferase (HPRT), and expressed as $2^{-\Delta C t}$.

\section{Western blot analysis}

After $6 \mathrm{~h}$ of crystal stimulation, THP-1 cells were lysed for $15 \mathrm{~min}$ with radioimmunoprecipitation assay buffer containing protease inhibitors (Sigma-Aldrich), phenylmethylsulphonyl fluoride, and orthovanadate (Sigma, Germany), on ice. Lysates were centrifuged, and total protein concentration was determined by bicinchoninic acid assay. An amount of $17 \mu$ g protein was separated in SDS-PAGE and transferred to polyvinylidene fluoride (PVDF) membranes for immunoblot analysis. AntiNLRP3, IL-1 $\beta$, cleaved-IL-1 $\beta$, and glyceraldehyde 3phosphate dehydrogenase (GAPDH) rabbit antibodies (Cell Signaling Technology, USA) were diluted at 1/ 1000.

\section{Histology and immunohistochemistry (IHC)}

The air pouch membranes were fixed in formol $4 \%$ during $24 \mathrm{~h}$ before dehydration and paraffin-embedding. Three-micrometer-thick sections were stained with hematoxylin and eosin (H\&E). Membrane thickness was measured on H\&E samples. The average of the thickness on 3 separate slides was calculated for each mouse. For IHC, the sections were incubated with primary antibodies targeting Iba1 to identify macrophages (ab5076, Abcam, UK), Ly6G to identify neutrophils (ab25377, Abcam), CD3 to identify $\mathrm{T}$ lymphocytes (ab5690, Abcam), and CD45R/B220+ for B lymphocytes (550286, BD Pharmingen, USA). Secondary antibodies were incubated at 1:400 for $2 \mathrm{~h}$, and streptavidin-HRP (P0397, 
Dako, USA) was incubated for $1 \mathrm{~h}$, both at room temperature. Staining was achieved with DAB (TA-125QHDX, Thermo Scientific), and counterstaining was performed with hematoxylin. Cells were considered positive when stained in brown. Brown-stained surfaces were quantified using the ImageJ software as previously described [14, 15].

\section{Statistical analysis}

Data are reported as mean \pm standard error of the mean (SEM). The Mann-Whitney tests were performed to compare the different conditions using GraphPad Prism 8.0 for Windows. The significance level was set at $p \leq$ 0.05 .

\section{Results}

Pro-inflammatory effects of human calcifications on human monocytes, macrophages, and tenocytes

We first observed that synthetic apatite crystals used as control contained larger elements than patients' calcifications. After grinding, we obtained particles with size (1-100 $\mu \mathrm{m}$ length) and morphology (round shape) close to the human calcifications (Fig. 1a) [3]. Therefore, we used the grinded synthetic crystals for the following experiments. First, we studied the effects of crystals on IL-1 $\beta$ released by cells of the monocyte/macrophage lineage. We observed that, when cultured with synthetic apatite or human crystals, monocytes and M-CSF or GM-CSF macrophages were able to increase significantly their release of IL-1 $\beta$ (Fig. 1b). These increased amounts of IL-1 $\beta$ in the culture supernatants were observed only when the cells had been previously primed overnight with LPS, as observed previously with other microcrystals [7]. Without LPS, there was no detection of IL- $1 \beta$ in the culture medium. IL- $1 \beta$ was detected in response to increasing stimuli from 250 to $1000 \mathrm{ng} / \mathrm{ml}$ (Supplementary figure S1). At the same crystal concentration (1 mg/ $\mathrm{ml})$, synthetic HA stimulation induced significantly higher levels of IL-1 $\beta$ released by M-CSF or GM-CSF macrophages compared to human calcification (Fig. 1b).

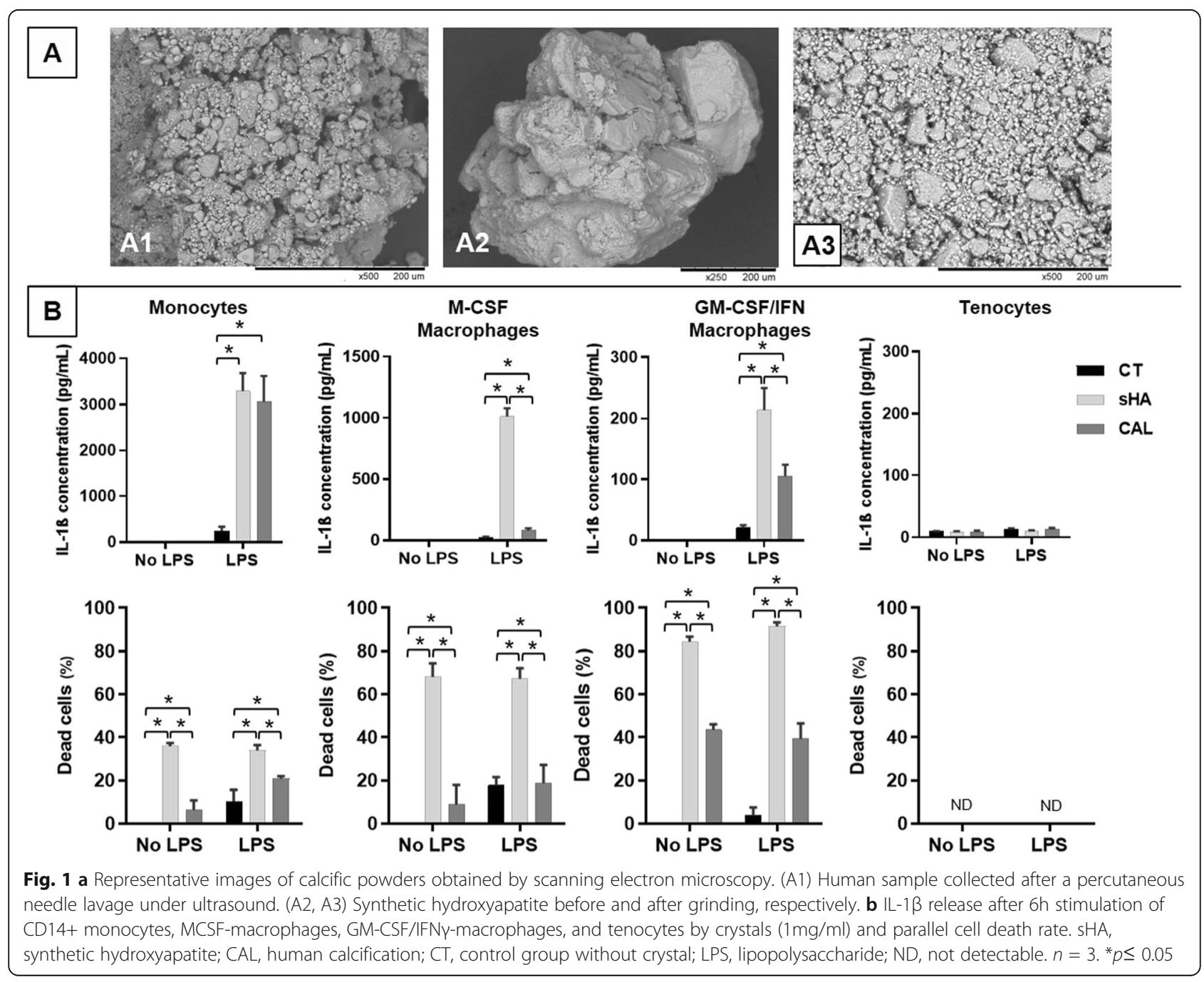


In parallel, we observed a significantly induced cell death in cultures with crystals compared to the control condition. As observed with IL- $1 \beta$ release, cell death was significantly higher with sHA than with patients' calcification but was equivalent between LPS-primed cells and not-primed cells. We also studied the effects of crystal stimulation on tenocytes, the major cell population of the tendon (Fig. 1b). We did not observe any significant release of IL-1 $\beta$ in tenocyte supernatants even after priming by LPS, nor any induced cell death, thus suggesting that macrophages are the key cells of the inflammation induced by the resorption of calcification.

\section{Pro-inflammatory effects of human calcifications on THP-} 1 macrophages

To go further in the mechanisms of action of crystals on macrophages, we then used the myeloid cell line THP-1, which was pre-treated with PMA to induce macrophage maturation and priming. This cell line has been previously used to study the inflammatory response to crystals [7].

First and as demonstrated previously with other crystals [11], we observed that secretion of IL-1 $\beta$ was significantly higher when stimulation was performed in FBSfree conditions (Fig. 2a). The following experiments were therefore carried out in an FBS-free medium. After crystal stimulation, an increased release of IL- $1 \beta$ was observed after $1 \mathrm{~h}$ and gradually increased within $24 \mathrm{~h}$ (Fig. $2 b)$. No IL-1 $\beta$ was detected when human calcifications were incubated alone in the medium without THP-1 cells (Fig. 2c). When crystals were applied at increasing concentrations, we observed a dose-dependent increase of IL-1 $\beta$ production for the two types of crystals, with a significantly higher IL-1 $\beta$ release after sHA stimulation at 250 and $500 \mu \mathrm{g} / \mathrm{ml}$ than with patients' apatite (Fig. 2d, $N=9$ patients). The percentage of dead cells also increased with the crystal concentrations and was

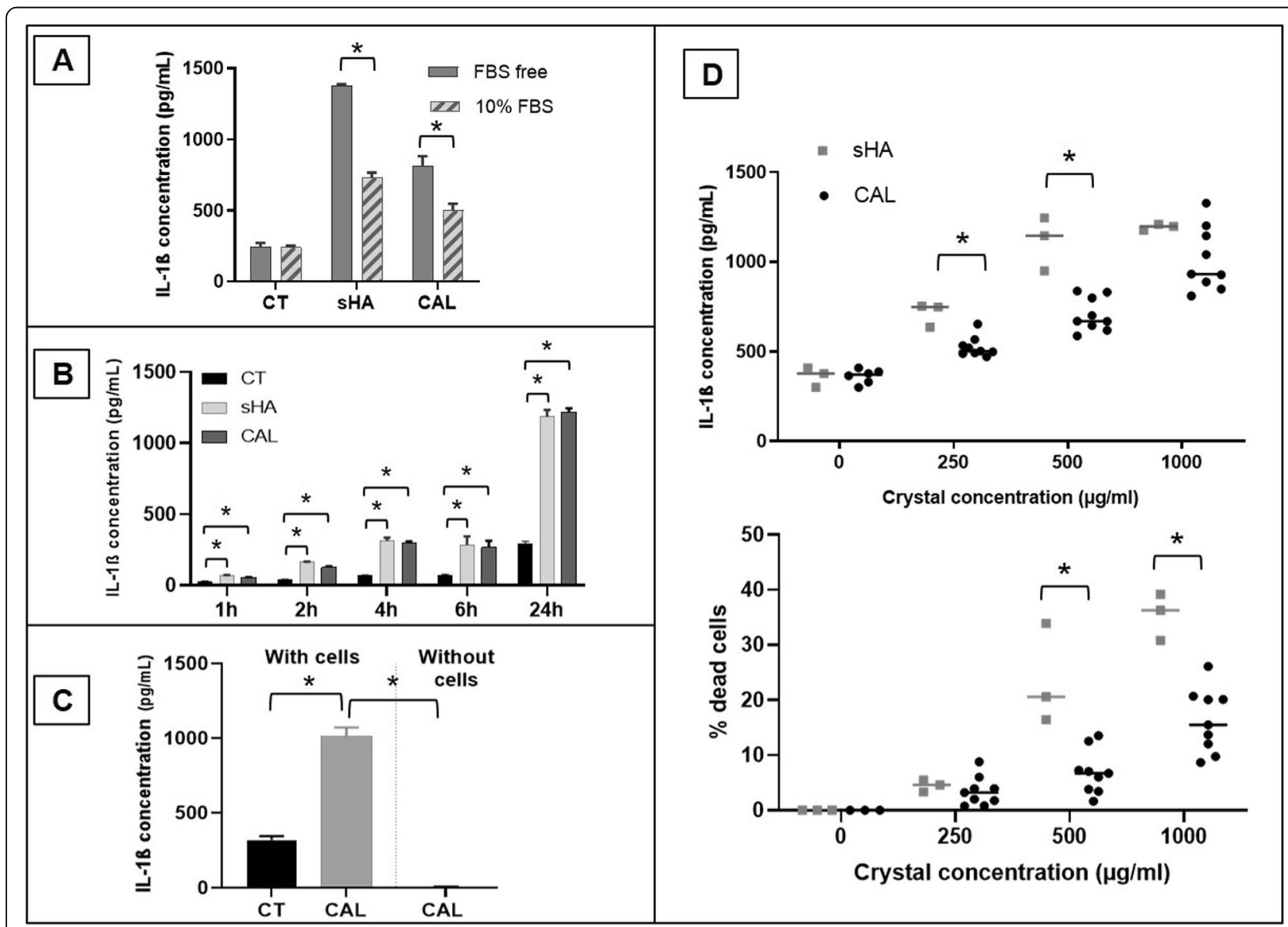

Fig. $2 \mathrm{IL}-1 \beta$ production by THP-1 cells after crystal stimulation. a Release of IL-1 $\beta$ by THP-1 cells cultured during $6 \mathrm{~h}$ with crystals $(1 \mathrm{mg} / \mathrm{ml})$ in media with or without $10 \%$ fetal bovine serum (FBS) $(n=3)$. b Kinetic of IL-1 $1 \beta$ production by THP-1 cells cultured with a patient's calcification $(C A L, 1 \mathrm{mg} / \mathrm{ml})$ and synthetic hydroxyapatite ( $\mathrm{sHA}, 1 \mathrm{mg} / \mathrm{ml}$ ) or without crystal $(C T)(n=3)$. c IL-1 $\beta$ release in cultures containing only crystals compared to THP-1 cells after crystal stimulation ( $N=3$ patients). $\mathbf{d}$ IL-1 $\beta$ quantification in supernatants of THP-1 after $6 \mathrm{~h}$ of crystal stimulation with increasing concentrations of calcifications of 9 different patients $(N=9)$. sHA, synthetic hydroxyapatite; $C A L$, human calcification; $C T$, control condition without crystals. ${ }^{*} p \leq 0.05$ 
significantly higher after sHA stimulation at 500 and $1000 \mu \mathrm{g} / \mathrm{ml}$ compared to human apatite (Fig. 2d). IL-6 release and IL- 8 release at $6 \mathrm{~h}$ were also quantified by ELISA in THP-1 supernatants: IL- 6 was not detectable while IL-8 level was not increased after crystal stimulation (data not shown).

The gene expression of $I L-1 \beta$ was increased in THP-1 cells after crystal stimulation as well as $I L-18$, another member of the IL-1 family. We also observed an increased expression of $N F-\kappa B$ and TGF $\beta 1$ with both sHA and patients' apatite. In contrast, there was no increase in $I L$-interleukin 1 receptor antagonist (1RA), IL-6, and $T N F \alpha$ gene expression (Fig. 3).

Finally, the release of IL- $1 \beta$ induced by sHA and patients' apatite was significantly reduced by the addition of an inhibitor of NF-kB (BAY-11-7085) as well as an inhibitor of caspase-1 (Z-YVAD-FMK) (Fig. 4a and Figure S2). Using Western blot analysis, we also found a significant decrease of cleaved IL-1 $\beta$ (mature form of IL-1 $\beta$ ) in cell lysates and supernatants although the inhibitor of caspase- 1 only reduced the release of cleaved IL- $1 \beta$ in supernatants but did not reduce the amount of cleaved IL-1 $\beta$ in cell lysates (Fig. 4b, c).
Pro-inflammatory effects of human calcifications in an air pouch mouse model

To confirm the inflammatory effect of patients' crystals, we next used the murine air pouch model. In both $\mathrm{C} 57 \mathrm{BL} / 6$ and $\mathrm{BALB} / \mathrm{c}$ mice, injection of patient's crystals or synthetic HA resulted in an infiltration of the membrane with a significantly enhanced membrane thickness as early as $6 \mathrm{~h}$ post-injection (Fig. 5a-c). Immunohistochemistry showed a significant infiltration of Iba1+ macrophages (Fig. 5c, d). Ly6G+ neutrophils were rarely present in the infiltrate as well as CD3+ T lymphocytes and CD45R/ B220+ B lymphocytes (data not shown). We also observed the presence of crystals (" $C$ " in Fig. 5c) included within the membrane $6 \mathrm{~h}$ after the injection. While the inflammatory infiltrates were equivalent in the two crystal groups, an increase in $I L-1 \beta$ gene expression was higher in the synthetic apatite group (Fig. 5e) and just approached the significance in the human calcification group at the dose of $2 \mathrm{mg} / \mathrm{ml}(p$ $=0.06$ ). The gene expression of $T N F \alpha$ and $I L-6$ was not increased in the crystals groups compared to the PBS group (data not shown).

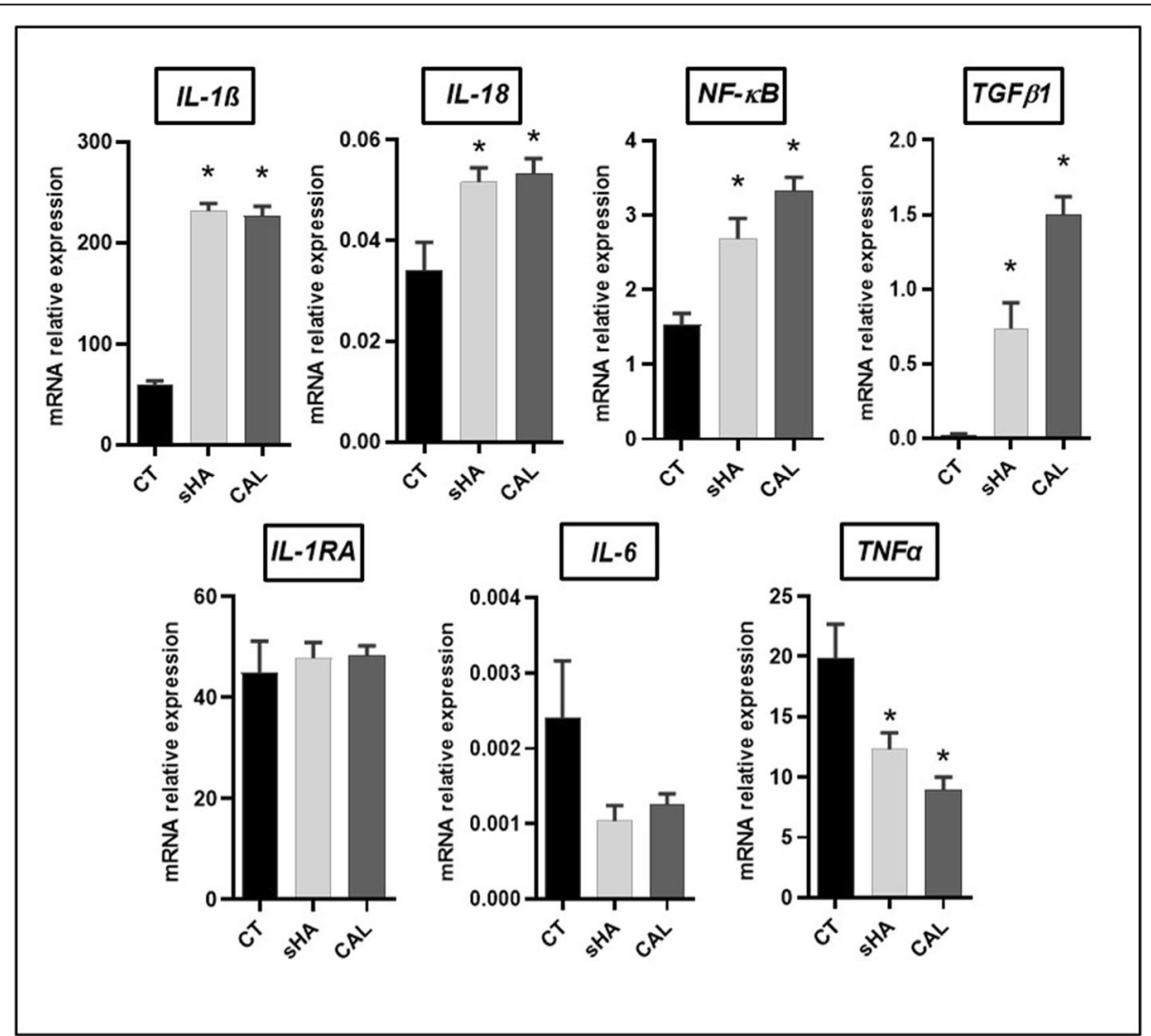

Fig. 3 THP-1 gene expression after 6 h of stimulation by crystals (synthetic hydroxyapatite (sHA) or human calcification (CAL) at $1 \mathrm{mg} / \mathrm{mL}$ ). Gene expression is expressed in relative expression $\left(2^{-\Delta C t}\right)$ with the HPRT gene used as a reference. $C T$, control condition without crystal. ${ }^{*} p \leq 0.05(n$ $=3)$ 


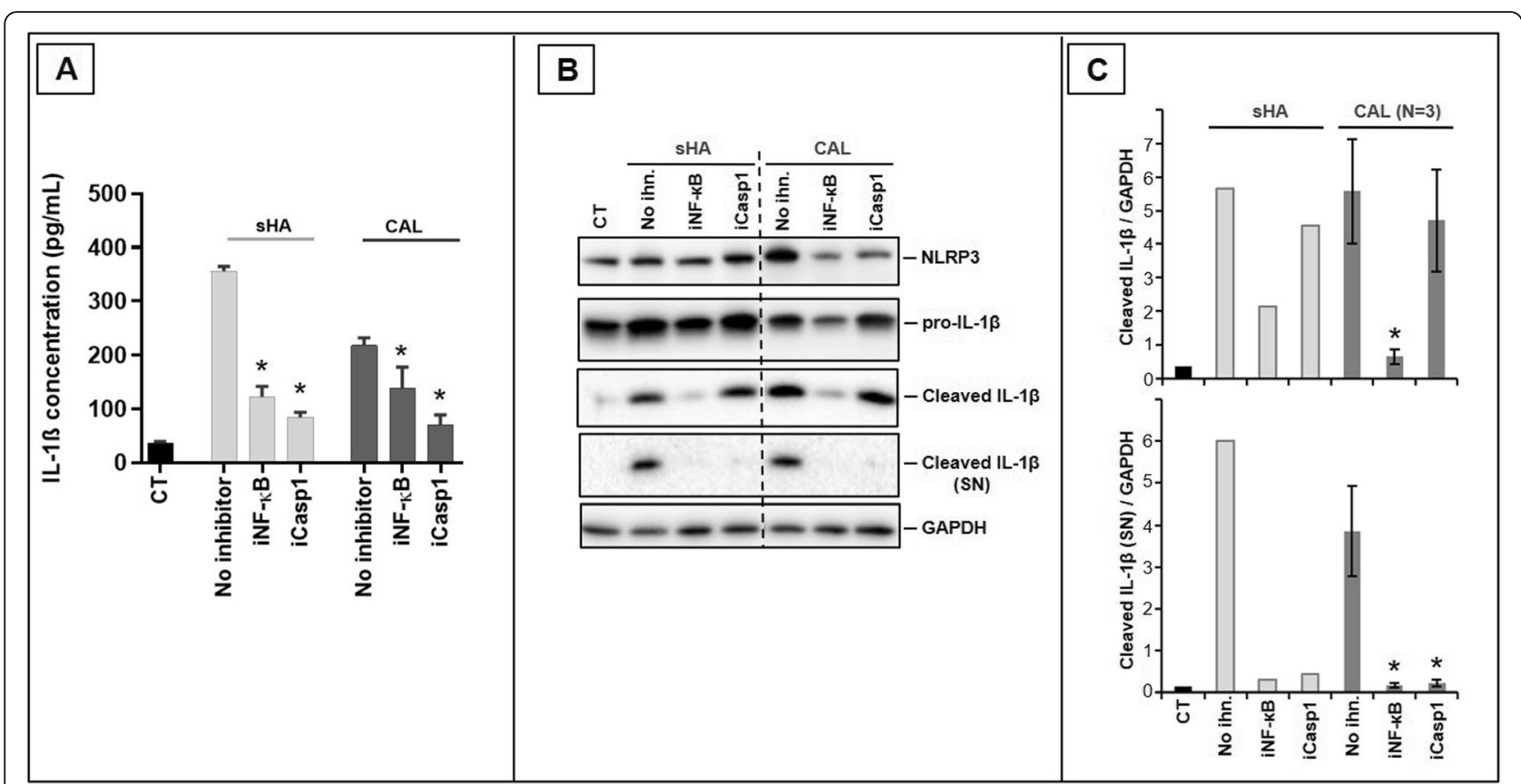

Fig. 4 Effects of a NF-KB inhibitor and a caspase-1 inhibitor on the secretion of IL-1 13 by THP-1 macrophages. a Quantification of IL-1 $\beta$ released into the medium after $6 \mathrm{~h}$ of stimulation by crystals $(1 \mathrm{mg} / \mathrm{ml})$ in the presence or absence of a NF-kB inhibitor (BAY-11-7085, 10 $\mu \mathrm{M})$ or a caspase-1 inhibitor (Z-YVAD-FMK, $10 \mu \mathrm{M})(n=3)$. b, c Effects of crystals and inhibitors on NLRP3 and IL-1 $\beta$ assessed by Western Blot on cell lysates and supernatants (SN). One representative patient out of 3 is presented in $\mathbf{b}$, and quantification of cleaved-IL-1 $\beta$ in cell lysates and supernatant is presented in c ( $N=3$ patients), with GAPDH used as an invariant protein. iNF-KB, NF-kB inhibitor; iCasp1, caspase-1 inhibitor; inh, inhibitor; sHA, synthetic hydroxyapatite; CAL, human calcification; $C$, control condition without crystals. ${ }^{*} p \leq 0.05$

\section{Discussion}

Even if the pro-inflammatory effects of the apatite crystals have been yet demonstrated through previous studies using synthetic hydroxyapatite $[7,8,10,11]$, we demonstrated here the inflammatory effects of crystals extracted from patients suffering from calcific tendinopathies, with their own characteristics in terms of size, shape, and protein content. Similar to MSU and CPPD crystal-induced inflammation, IL-1 $\beta$ is the central cytokine in the process, and its release depends on NLRP3 inflammasome activation. In gout and acute CPP crystal arthritis, the crystals taken up by macrophages first enhance pro-IL-1 $\beta$ expression during the priming phase and then promote the assembly and activation of the NLRP3 inflammasome. The NLRP3 inflammasomes are formed by the recruitment of the adaptor protein ASC and subsequent recruitment of caspase-1 [16, 17]. Caspase- 1 activates the pro-inflammatory cytokines IL$1 \beta$ and IL-18 by cleaving their respective precursor proteins, pro-IL- $1 \beta$, and pro-IL-18. Then, IL-1 $\beta$ drives further inflammation by promoting (1) cytokine and chemokine production, (2) endothelial cell activation, (3) PGE2 production, and (4) neutrophil recruitment [14].

We showed in vitro that human calcifications were able to induce the release of IL- $1 \beta$ by human monocytes, macrophages, and the myeloid cell line THP-1 but not tenocytes. As observed with other microcrystals [7], cell priming using LPS or PMA was necessary to provide the first signal for IL-1 $\beta$ production. Following this priming phase, we also observed that patient's crystals enhanced mRNA expression of $I L-1 \beta$, as well as $I L-18, N F-\kappa B$, and TGF $\beta 1$ (Fig. 3). Crystals from 9 different patients induced IL- $1 \beta$ release from THP-1 cells in a time- and dose-dependent manner, but IL- 6 was not detectable in culture supernatants at $6 \mathrm{~h}$ of stimulation probably because it is produced later [11]. The central role of IL-1 in apatite crystal-related inflammation is also supported by some preliminary clinical data showing that administration of IL1-RA (anakinra) significantly reduced the pain experienced by patients during acute apatiteinduced joint pain $[18,19]$. In parallel with the release of IL-1 $\beta$, we observed an increase in cell death (Figs. 1b and $2 \mathrm{~d}$ ), which probably participates in the release of additional IL-1 $\beta$ through the phenomenon of pyroptosis [17]. Moreover, inhibition of NF- $k B$ significantly reduced the production and release of the matured form of IL- $1 \beta$ $(17 \mathrm{kDa}$, Fig. $4 \mathrm{~b}, \mathrm{c})$. The inhibition of caspase- 1 similarly reduced the release of matured IL-1 $\beta$ into the culture supernatant but did not prevent the maturation of this cytokine in cell lysates (Fig. 4b, c). Our current hypothesis is that other caspases such as caspase- 8 could be implicated in IL-1 $\beta$ maturation while caspase- 1 would be 


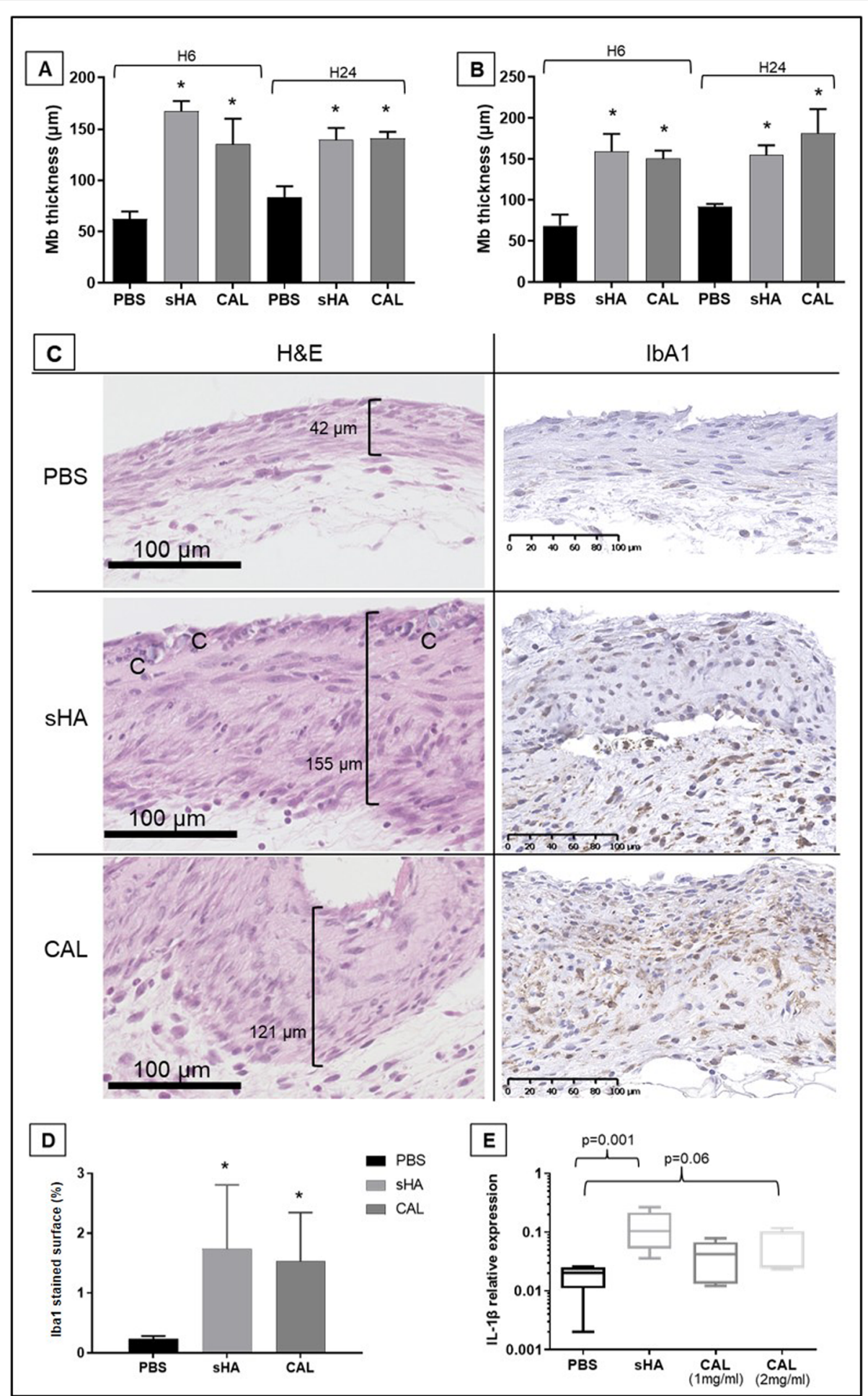

Fig. 5 In vivo effects of human calcifications in a mouse air pouch model. a Assessment of membrane thickness (H\&E staining) 6 and $24 \mathrm{~h}$ after crystals injection ( $1 \mathrm{mg} / \mathrm{ml})$ in C57BL/6 mice ( $\mathrm{N}=3-5 / \mathrm{group})$. b Assessment of membrane thickness 6 and $24 \mathrm{~h}$ after crystals injection (1 mg/ml) in BALB/c mice ( $N=4-5 / g r o u p)$. c Representative images of H\&E and Iba1 staining $6 \mathrm{~h}$ after the injection for each group in C57BL/6 mice. $\mathbf{d}$ Quantification of the Iba1+ macrophage infiltration $6 \mathrm{~h}$ after the injection in C57BL/6 mice ( $N=3-5 /$ group). Results are expressed as Iba $1+$ stained surface (\%) as assessed using the Image J software. e $I L-1 \beta$ gene expression in the air pouch membranes $6 \mathrm{~h}$ after the injection of crystals ( 1 or $2 \mathrm{mg} / \mathrm{ml}$ as indicated) ( $N=5 /$ group). Gene expression is expressed in relative expression $\left(2^{-\Delta C t}\right)$ with the HPRT gene used as a reference. sHA, synthetic apatite; CAL, human calcification; H\&E, hematoxylin and eosin; C, crystals. ${ }^{*} p<0.05$ 
necessary for IL-1 $\beta$ release through gasdermin D maturation, pore formation, and pyroptosis [20].

In vivo, human calcifications were able to induce a thickening of air pouch membranes with an infiltrate composed mainly of macrophages, showing once again the contribution of these cells in the response to crystal stimulation. However, the increased expression of $I L-1 \beta$ in the membranes was higher with synthetic apatite suggesting a lower inflammatory activity of patients' crystals in these experiments. This lower inflammatory potential of human calcifications compared to synthetic apatite was also observed when crystals were incubated with human macrophages. This difference could first be explained by a different size and shape of human and synthetic crystals. Indeed, small and needle-shaped crystals were more likely to produce an IL-1 $\beta$-mediated inflammatory response compared to large and spherical crystals $[8,21]$. In our samples, particle size varied from 3 to $300 \mu \mathrm{m}$ [3], with a spherical morphology. Although the particle size and shape were grossly similar between patients and grinded synthetic HA, we cannot exclude that particle heterogeneity would lead to variable pro-inflammatory effects on cells. We can also hypothesize that only a portion of the particles was involved in the induction of IL- $1 \beta$ secretion and could vary between patients depending on the disparity in crystal size within the samples.

Secondly, the protein present on crystals may also have a role. It has been shown that MSU crystals can be coated by several proteins (albumin, ovalbumin, immunoglobulin (Ig), fibrinogen, fibronectin, lysozyme, apolipoproteins, and high- and low-density lipoproteins (HDL and LDL)) [22-26] and that these adsorbed proteins could influence the inflammatory properties of MSU crystals. For example, MSU crystals isolated from sites of gouty inflammation are coated with immunoglobulins (mainly IgG), whose surface concentrations decline as the inflammation resolves (inversely correlating with a rise in apolipoprotein B surface coating), suggesting a regulatory role of these elements in acute gout attack [27, 28]. The effects of protein coating on CPPD crystal-induced inflammation have also been recently studied [29]. As observed in our experiments, when monoclinic calcium pyrophosphate dihydrate (m-CPPD) crystals were incubated with FBS, and the release of IL$1 \beta$ by THP- 1 was significantly decreased. Otherwise, BSA-coated crystals were less likely able to induce IL-1 $\beta$ release. Adsorption of serum proteins on crystals led to a decreased ATP secretion and a disturbance of mitochondrial membrane depolarization was observed leading to an alteration of NLRP3 inflammasome activation in the presence of serum proteins. In addition, albumin adsorption on crystals could modulate crystal-induced cell responses through crystal/cell-membrane interaction [29]. By proteomic analysis, we have found in a previous study similarities with proteins that can be coated on MSU (fibronectin, albumin, apolipoproteins, fibrinogen) [3]. In addition, several proteins implicated in the regulation of inflammation and immune reactions (osteopontin, osteoprotegerin, or periostin) were previously found associated with patients' crystals [3]. However, the influence of proteins absorbed on human apatite crystals on their inflammatory properties has not been studied yet and may be the purpose of future studies.

\section{Conclusion}

As synthetic hydroxyapatite, human calcifications were able to induce an inflammatory response resulting in the production of IL- $1 \beta$ after NF- $\mathrm{KB}$ activation and through NLRP3 inflammasome. These findings are consistent with preliminary data about the efficacy of IL1-RA (anakinra) in acute apatite-induced joint pain. In some experiments, IL-1 $\beta$ induction was lower with human calcifications compared to synthetic apatite. Differences in size, shape, and protein content may explain this observation. Further studies would be necessary to explore the potential role of protein in the regulation of the inflammation induced by the crystals.

\section{Abbreviations \\ CAL: Human calcification; CPPD: Calcium pyrophosphate dihydrate; Ct: Cycle threshold; CT: Control group; FBS: Fetal bovine serum; GAPD \\ H: Glyceraldehyde 3-phosphate dehydrogenase; GM-CSF: Granulocyte- macrophage colony-stimulating factor; H\&E: Hematoxylin and eosin; HPRT: Hypoxanthine-guanine phosphoribosyl transferase; IFN- $y$ : Interferon gamma; IHC: Immunohistochemistry; IL: Interleukin; IL1RA: Interleukin 1 receptor antagonist; LPS: Lipopolysaccharide; M-CSF: Macrophage colony- stimulating factor; MSU: Monosodium urate; NF-KB: Nuclear factor-kappa B; NLRP3: NOD-like receptor family, pyrin domain containing 3; PBS: Phosphate- buffered saline; PCR: Polymerase chain reaction; PMA: Phorbol 12-myristate \\ 13-acetate; RNA: Ribonucleic acid; SEM: Standard error of the mean; sHA: Synthetic hydroxyapatite; TGF- $\beta$ : Transforming growth factor beta; TNF: Tumor necrosis factor}

\section{Supplementary Information}

The online version contains supplementary material available at https://doi. org/10.1186/s13075-021-02516-9.

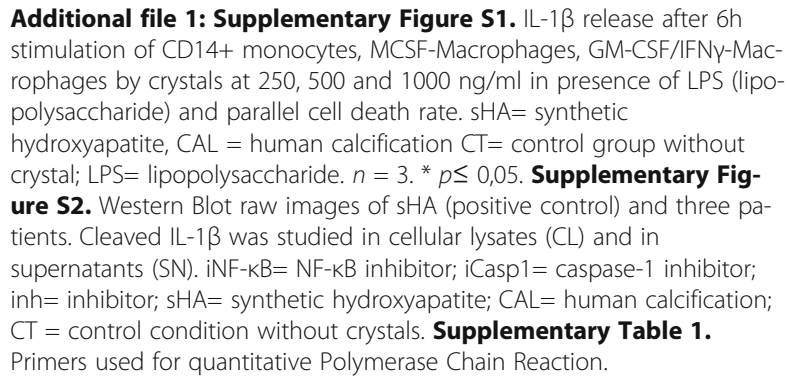

Acknowledgements

Not applicable.

Authors' contributions

$J H, J D L, R B, C C, F B$, and CDL have contributed to the acquisition and analysis of the data. $J H, B L G, F B$, and $C D L$ have contributed to the conception and 
the design of the work and have drafted the manuscript. All authors read and approved the final manuscript.

\section{Funding}

The study was performed with the financial support from the "Fondation Arthritis Recherche et Rhumatismes" and the "French Society for Rheumatology."

\section{Availability of data and materials}

The datasets used and/or analyzed during the current study are available from the corresponding author on reasonable request.

\section{Declarations}

\section{Ethics approval and consent to participate}

Animal experiments were carried out in accordance with the institutional guidelines and were approved by the French ethical committee CEEA Pays de la Loire and by local veterinary services (approval number APAFIS\#49692016041411376797v3).

\section{Consent for publication}

Not applicable.

\section{Competing interests}

The authors declare that they have no competing interests.

\section{Author details}

${ }^{1}$ INSERM UMR1238, Bone Sarcoma and Remodeling of Calcified Tissues, Faculté de Médecine de Nantes, 1 rue Gaston Veil, 44035 Nantes Cedex 1, France. ${ }^{2}$ Rheumatology Department, Nantes University Hospital, 44093 Nantes, France. ${ }^{3}$ Nantes University Hospital, 44093 Nantes, France. ${ }^{4}$ Current Address: McKay Orthopedic Research Laboratory, University of Pennsylvania, 307A Stemmler Hall, 3450 Hamilton Walk, Philadelphia, PA 19104-6081, USA.

\section{Received: 26 January 2021 Accepted: 20 April 2021}

\section{Published online: 29 April 2021}

\section{References}

1. Darrieutort-Laffite C, Blanchard F, Le Goff B. Calcific tendonitis of the rotator cuff: from formation to resorption. Joint Bone Spine. 2018;85(6):687-92. https://doi.org/10.1016/j.jbspin.2017.10.004 Epub 2017 Nov 28.

2. Uhthoff HK, Loehr JW. Calcific tendinopathy of the rotator cuff: pathogenesis, diagnosis and management. J Am Acad Orthop Surg. 1997; 5(4):183-91. https://doi.org/10.5435/00124635-199707000-00001.

3. Darrieutort-Laffite C, Arnolfo P, Garraud T, Adrait A, Couté Y, Louarn G, et al. Rotator cuff tenocytes differentiate into hypertrophic chondrocyte-like cells to produce calcium deposits in an alkaline phosphatase-dependent manner. J Clin Med. 2019;8(10):1544. https://doi.org/10.3390/jcm8101544.

4. Uhthoff HK. Calcifying tendinitis, an active cell-mediated calcification. Virchows Arch A Pathol Anat Histol. 1975;366(1):51-8. https://doi.org/10.1 007/BF00438677.

5. Archer RS, Bayley Jl, Archer CW, Ali SY. Cell and matrix changes associated with pathological calcification of the human rotator cuff tendons. J Anat. 1993:182:1-11

6. Nakase T, Takeuchi E, Sugamoto K, Kaneko M, Tomita T, Myoui A, et al. Involvement of multinucleated giant cells synthesizing cathepsin $\mathrm{K}$ in calcified tendinitis of the rotator cuff tendons. Rheumatology (Oxford). 2000; 39(10):1074-7. https://doi.org/10.1093/rheumatology/39.10.1074.

7. Pazár B, Ea HK, Narayan S, Kolly K, Bagnoud N, Chobaz V, et al. Basic calcium phosphate crystals induce monocyte/macrophage IL-1secretion through the NLRP3 inflammasome in vitro. J Immunol. 2011;186:2495-502. https://doi. org/10.4049/jimmunol.1001284 Epub 2011 Jan 14.

8. Jin C, Frayssinet P, Pelker R, Cwirka D, Hu B, Vignery A, et al. NLRP3 inflammasome plays a critical role in the pathogenesis of hydroxyapatiteassociated arthropathy. Proc Natl Acad Sci U S A. 2011;108(36):14867-72. https://doi.org/10.1073/pnas.1111101108. Epub 2011 Aug 19.

9. Kowanko IC, Gordon TP, Rozenbilds MA, Brooks PM, Roberts-Thomson PJ. The subcutaneous air pouch model of synovium and the inflammatory response to heat aggregated gammaglobulin. Agents Actions. 1986;18(3-4): 421-8. https://doi.org/10.1007/BF01965007.
10. Prudhommeaux F, Schiltz C, Lioté F, Hina A, Champy R, Bucki B, et al. Variation in the inflammatory properties of basic calcium phosphate crystals according to crystal type. Arthritis Rheum. 1996;39(8):1319-26. https://doi. org/10.1002/art.1780390809.

11. Campillo-Gimenez L, Renaudin F, Jalabert M, Gras P, Gosset M, Rey C, et al. Inflammatory potential of four different phases of calcium pyrophosphate relies on NF-kB activation and MAPK pathways. Front Immunol. 2018;9:2248. https://doi.org/10.3389/fimmu.2018.02248 eCollection 2018.

12. Nakayama M. Macrophage recognition of crystals and nanoparticles. Front Immunol. 2018;9:103. https://doi.org/10.3389/fimmu.2018.00103 eCollection 2018.

13. Grases F, Muntaner-Gimbernat L, Vilchez-Mira M, Costa-Bauzá A, Tur F, Prieto RM, et al. Characterization of deposits in patients with calcific tendinopathy of the supraspinatus. Role of phytate and osteopontin. J Orthop Res. 2015; 33(4):475-82.

14. Najm A, Masson FM, Preuss P, Georges S, Ory B, Quillard T, et al. MicroRNA$17-5 p$ reduces inflammation and bone erosions in mice with collageninduced arthritis and directly targets the JAK/STAT pathway in rheumatoid arthritis fibroblast-like synoviocytes. Arthritis Rheumatol. 2020;72(12):2030-9. https://doi.org/10.1002/art.41441 Epub 2020 Oct 29.

15. Boutet MA, Najm A, Bart G, Brion R, Touchais $S$, Trichet $V$, et al. IL-38 overexpression induces anti-inflammatory effects in mice arthritis models and in human macrophages in vitro. Ann Rheum Dis. 2017;76(7):1304-12. https://doi.org/10.1136/annrheumdis-2016-210630 Epub 2017 Mar 13.

16. McCarthy GM, Dunne A. Calcium crystal deposition diseases - beyond gout. Nat Rev Rheumatol. 2018;14(10):592-602. https://doi.org/10.1038/s41584-018-0078-5.

17. So AK, Martinon F. Inflammation in gout: mechanisms and therapeutic targets. Nat Rev Rheumatol. 2017;13(11):639-47. https://doi.org/10.1038/ nrrheum.2017.155 Epub 2017 Sep 28.

18. Sota O, Sunday I. Subcutaneous injection of anakinra in patients with shoulder pain due to rotator cuff tendonitis and subacromial bursitis. Pain Med. 2004;5(2):229-30. https://doi.org/10.1111/j.1526-4637.2004.04022.x.

19. Zufferey $P$, Valcov $R$, Thomas M, Dumusc A, Forien M, So A, et al. Efficacy of anakinra in acute hydroxyapatite calcification-induced joint pain: a retrospective study of 23 cases. Joint Bone Spine. 2019;86(1):83-8. https:// doi.org/10.1016/j.jbspin.2018.05.008 Epub 2018 Jun 5.

20. Schneider KS, Groß CJ, Dreier RF, Saller BS, Mishra R, Gorka O, et al. The inflammasome drives GSDMD-independent secondary pyroptosis and IL-1 release in the absence of caspase-1 protease activity. Cell Rep. 2017;21(13): 3846-59. https://doi.org/10.1016/j.celrep.2017.12.018.

21. Lebre F, Sridharan R, Sawkins MJ, Kelly DJ, O'Brien FJ, Lavelle EC. The shape and size of hydroxyapatite particles dictate inflammatory responses following implantation. Sci Rep. 2017;7(1):2922. https://doi.org/10.1038/s41 598-017-03086-0.

22. Kozin F, McCarty DJ. Protein adsorption to monosodium urate, calcium pyrophosphate dihydrate, and silica crystals: relationship to the pathogenesis of crystal-induced inflammation. Arthritis Rheum. 1976; 19(Suppl 3):433-8. https://doi.org/10.1002/1529-0131(197605/06)19:3+< 433:.:aid-art1780190718>3.0.co;2-u.

23. Kozin F, McCarty DJ. Protein binding to monosodium urate monohydrate, calcium pyrophosphate dihydrate, and silicon dioxide crystals. I. Physical characteristics. J Lab Clin Med. 1977;89(6):1314-25.

24. Terkeltaub R, Martin J, Curtiss LK, Ginsberg MH. Apolipoprotein B mediates the capacity of low density lipoprotein to suppress neutrophil stimulation by particulates. J Biol Chem. 1986;261(33):15662-7.

25. Abramson S, Hoffstein ST, Weissmann G. Superoxide anion generation by human neutrophils exposed to monosodium urate. Arthritis Rheum. 1982; 25(2):174-80. https://doi.org/10.1002/art.1780250210.

26. Scanu A, Luisetto R, Oliviero F, Gruaz L, Sfriso P, Burger D, et al. High-density lipoproteins inhibit urate crystal-induced inflammation in mice. Ann Rheum Dis. 2015;74(3):587-94. https://doi.org/10.1136/annrheumdis-2013-203803 Epub 2013 Dec 10.

27. Ortiz-Bravo E, Sieck MS, Schumacher HR Jr. Changes in the proteins coating monosodium urate crystals during active and subsiding inflammation. Immunogold studies of synovial fluid from patients with gout and of fluid obtained using the rat subcutaneous air pouch model. Arthritis Rheum. 1993;36(9):1274-85. https://doi.org/10.1002/art.1780360912.

28. Cherian PV, Schumacher HR Jr. Immunochemical and ultrastructural characterization of serum proteins associated with monosodium urate crystals (MSU) in synovial fluid cells from patients with gout. Ultrastruct Pathol. 1986;10(3):209-19. https://doi.org/10.3109/01913128609032219. 
29. Renaudin F, Sarda S, Campillo-Gimenez L, Séverac C, Léger T, Charvillat C, et al. Adsorption of proteins on m-CPPD and urate crystals inhibits crystalinduced cell responses: study on albumin-crystal interaction. J Funct Biomater. 2019;10(2):18. https://doi.org/10.3390/jfb10020018.

\section{Publisher's Note}

Springer Nature remains neutral with regard to jurisdictional claims in published maps and institutional affiliations.

Ready to submit your research? Choose BMC and benefit from:

- fast, convenient online submission

- thorough peer review by experienced researchers in your field

- rapid publication on acceptance

- support for research data, including large and complex data types

- gold Open Access which fosters wider collaboration and increased citations

- maximum visibility for your research: over $100 \mathrm{M}$ website views per year

At BMC, research is always in progress.

Learn more biomedcentral.com/submissions 